\title{
Keratopigmentation: Is it a Miracle or an Adventure?
}

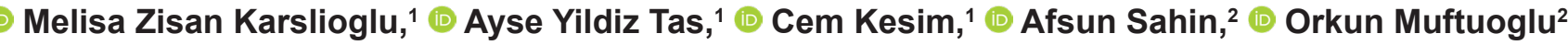 \\ 'Department of Ophthalmology, Koc University Hospital, Istanbul, Turkey \\ ${ }^{2}$ Department of Ophthalmology, Koc University Faculty of Medicine, Istanbul, Turkey
}

\begin{abstract}
Objectives: This study is an analysis of the cosmetic and functional results of patients who underwent keratopigmentation (KTP).

Methods: Sixteen eyes of 16 patients, 7 females (43.75\%) and 9 males (56.25\%) were included in the study. Intrastromal and superficial manual KTP were performed under general anesthesia. Patients with no light perception or with only light perception but total corneal opacification, prosthetic contact lens intolerance, or unwillingness to use a contact lens were studied. The main outcomes were postoperative patient's satisfaction, cosmetic results, pigment stabilization and surgical complications. A grading system (0-5 points) was used to assess patient satisfaction and the cosmetic results.

Results: The mean age of the patients was 30.5 12.06 years (range: 16-53 years). Black pigment was used in 10 patients (62.5\%), a brownish color in 5 patients (31.25\%) and a greenish, yellow, blue, and black color pigmentation was used for I patient (6.25\%). The mean follow-up was 29.3I 15.45 months (range: 8-52 months). In 2 of I6 patients, mild to moderate pigment loss was seen 12 months after the surgery and superficial KTP was repeated. Minimal pigment loss was seen in 5 patients, but the cosmetic results were satisfactory and no secondary surgical procedure was required. Pigment leakage underneath the conjunctiva was seen in only I patient. Otherwise, there were no complications associated with keratopigmentation. The postoperative mean patient satisfaction score was $4.18 \pm 0.75$ points (range: $3-5$ points).

Conclusion: KTP is a safe surgical procedure that is easy to learn and perform, does not require expensive materials, and avoids more extensive and invasive reconstructive ocular procedures. Corneal KTP may have a great impact on future ophthalmic surgical practice from both therapeutic and cosmetic perspectives.

Keywords: Corneal opacification, corneal tattoo, keratopigmentation.
\end{abstract}

\section{Introduction}

Corneal keratopigmentation (KTP) or corneal tattooing has been performed for many years (I). Galen (I3I-2IO AD) is considered to be the first person to apply the technique, masking corneal opacity with reduced copper sulphate (2-4). Products such as metallic powders, gold and platinum chloride, India ink, Chinese ink, organic dyes, animal uveal pigment, and soot have been used for this procedure (5-7). However, for various reasons, KTP did not become commonplace. A satisfactory appearance could require several combinations, and fading of the color was a problem (8).

In recent years, KTP has begun to be used for cosmetic reasons, such as elective change of the apparent color of the eye (9), and for functional disabilities, such as iris loss, atrophy, or trauma causing sensitivity to glare, photophobia, or monocular diplopia $(3,5,10-15)$. For patients with disabled eyes, cosmetic reconstruction may be necessary for well-being. Prosthetic contact lenses, penetrating keratoplasty, evisceration, enucleation, and, more recently, KTP, are treatment options $(2,11,13,16,17)$. A smooth ocular surface is the primary factor for appropriate contact lens fit. Penetrating keratoplasty has risks of infection and graft rejection, and it is ethically unacceptable to use donor corneas for cosmetic purposes (16). Evisceration and enucleation are serious sur-

Address for correspondence: Melisa Zisan Karslioglu, MD. Koc Universitesi Hastanesi, Goz Hastaliklari Anabilim Dali, Istanbul, Turkey

Phone: +90 8502508250 E-mail: mzkarslioglu@gmail.com 
gical procedures. KTP could be a very beneficial option, as it is a less invasive operation, has a high patient satisfaction rate, a smaller cost, and potential accessibility (I3).

In order to reduce the potential effects of a sensation of a foreign body and activation of the inflammatory response, micronized mineral pigments with smaller particles are now preferred (8). The early intrastromal techniques could not eliminate the possibility of permanent superficial corneal opacity (I I). Superficial KTP may be an alternative for patients with disfigured, blind eyes with corneal opacities, leukomas, or neovascularization (18). It has been demonstrated that superficial KTP can be a conservative and precise method to treat leukomatous lesions (2).

This study was an examination of the cosmetic and functional results of patients who underwent KTP at a single center.

\section{Methods}

\section{Study Design}

This was a retrospective analysis of a consecutive series of interventional and non-randomized cases.

\section{Patients}

Sixteen eyes of 16 patients, 7 females (43.75\%) and 9 males (56.25\%) were included in the study. Intrastromal and superficial manual KTP was performed under general anesthesia. The records of patients with no light perception or with only light projection perception and total corneal opacification, and those who had a prosthetic contact lens intolerance or were unwilling to wear a lens were analyzed. The tenets of the Declaration of Helsinki were observed throughout.

\section{Surgical Technique}

All intrastromal and superficial manual KTP procedures were performed by a single, experienced surgeon (OM) and mi- cronized mineral pigments (Commercial tattoo ink; Intenze Products Austria $\mathrm{GmbH}$, Kalsdorf, Austria) were used under general anesthesia. For intrastromal manual KTP, the center of cornea was marked with a caliper and the pupil diameter was designated using a 3 or $4 \mathrm{~mm}$ radial keratotomy optic zone marker (Katena, Inc., Parsippany, NJ, USA), as shown in Figure I. Radial incisions (4-5 in number) to midstromal depth (approximately $40-50 \%$ of corneal thickness) from the margin of the marked pupilla to the limbus were performed with a $45^{\circ}$ knife (ophthalmic slit knife, \#806599256I; Alcon Laboratories Inc., Fort Worth, TX, USA), and a microcrescent knife (angled crescent knife, \#A9900-02; Alcon Laboratories Inc., Fort Worth, TX, USA) was used to gently perform an intralamellar dissection, leaving the pupillary area intact. The dissection was continued until the dissector reached the nearest incision on both sides. The appropriate color pigment was injected into the peripheral dissected cornea using a 30-gauge cannula. To draw the pupilla, an arcuate incision was cautiously made, avoiding the radial incisions. The pupil was then stained by injecting black pigment via a 30 -gauge cannula.

Superficial manual KTP was used in cases where intrastromal KTP was not sufficient to provide a satisfactory cosmetic appearance because of superficial corneal opacities or lesions over the cornea. A drop of color pigment was put on the cornea and then manual micropunctures were performed to the superficial layers of the cornea with a 27 -gauge needle. This procedure can be repeated until a satisfactory cosmetic appearance is achieved.

\section{Main Outcome}

The main outcomes were postoperative patient satisfaction, cosmetic results, pigment stabilization, and surgical complications. A grading system ( $0-5$ points) was used to measure patient satisfaction and cosmetic results (Table I).
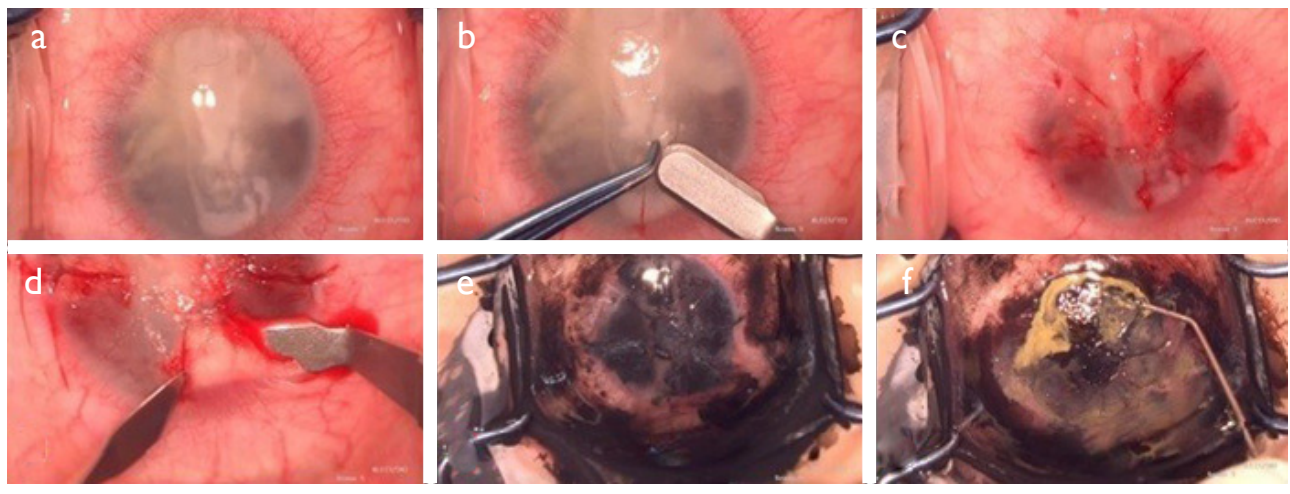

Figure I. Intrastromal manual keratopigmentation-surgical technique. (a) Total corneal opacification and band keratopathy; (b) Gentle dissection of the marked center of the cornea for pupil staining; (c) Radial incisions from the border of the marked pupil to the limbus with a $45^{\circ} \mathrm{knife}$; (d) Intrastromal dissection of the peripheral cornea with a microcrescent knife; (e) Intrastromal color pigment injection; (f) Mixing of brown and yellow-brown colors to achieve a satisfactory result. 
Table I. The questionnaire used by patients to assess their level of satisfaction and the cosmetic results after keratopigmentation

\begin{tabular}{lc}
$\begin{array}{l}\text { Question: How would you describe your } \\
\text { satisfaction level and cosmetic results? }\end{array}$ & Points \\
\hline Unsatisfactory & 0 \\
Minimally satisfactory & I \\
Moderately satisfactory & 2 \\
Mostly satisfactory & 3 \\
Satisfactory & 4 \\
Totally satisfactory & 5
\end{tabular}

\section{Statistical Analysis}

Statistical analysis was performed with IBM SPSS Statistics for Windows, Version 23 (IBM Corp., Armonk, NY, USA).

\section{Results}

Sixteen eyes of 16 patients, 7 females (43.75\%) and 9 males $(56.25 \%)$ were included in the study. The mean age of the patients was $30.5 \pm 12.06$ years (range: $16-53$ years). In 10 patients $(62.5 \%)$, a black pigment was applied, in 5 patients (31.25\%), a brownish pigment was used, and in I patient (6.25\%), greenish, yellow, blue, and black pigments were used (Table 2).

Table 2. Demographic data of the corneal keratopigmentation patients, surgical procedures, and pigments used

\begin{tabular}{|c|c|c|c|c|c|c|c|}
\hline Patient no & Sex & Age (years) & Diagnosis & Indication & Visual acuity & $\begin{array}{c}\text { KTP procedures } \\
\text { (intrastromal, superficial, } \\
\text { or both, and intrastromal } \\
\text { pigment injection) }\end{array}$ & Pigment color \\
\hline 1 & $F$ & 18 & CGLC & $\mathrm{CLI}$ & $\mathrm{LP}(+)$ & Both & Brown \\
\hline 2 & M & 25 & TEI & CLFP & $\operatorname{LP}(-)$ & Both & Brown \\
\hline 3 & M & 32 & CGLC & CLFP & LP (-) & Both & Black \\
\hline 4 & $M$ & 19 & TEI & CLUW & LP (-) & Both & Black \\
\hline 5 & $M$ & 39 & TEI, RD, S-oil, BK & CLFP & LP (-) & $\begin{array}{l}\text { Both and intrastromal } \\
\text { pigment injection } \\
\text { (due to megalocornea) }\end{array}$ & Black \\
\hline 6 & $\mathrm{~F}$ & 43 & $\begin{array}{c}\mathrm{KCN}-\mathrm{HS} \\
\text { S/P PK and GLCS }\end{array}$ & CLFP & LP (-) & Both & Black \\
\hline 7 & $M$ & 19 & WI & $\mathrm{CLI}$ & LP (-) & Both & Black \\
\hline 8 & M & 46 & TEI & CLUW & LP (-) & Both & Black \\
\hline 9 & $\mathrm{~F}$ & 16 & $\mathrm{MO}$ and GLC & CLFP & LP $(-)$ & Both & Black \\
\hline 10 & $\mathrm{~F}$ & 53 & TEI & CLUW & $\operatorname{LP}(-)$ & Both & Black \\
\hline II & $M$ & 45 & TEI, RD, S-oil, BK & $\begin{array}{l}\text { CLFP } \\
\text { CLUW }\end{array}$ & LP (-) & Both & $\begin{array}{l}\text { Blue, yellow, } \\
\text { greenish, black }\end{array}$ \\
\hline 12 & $\mathrm{~F}$ & 18 & $M C$ and $N$ & CLFP & $\mathrm{LP}(+) \mathrm{P}(+)$ & $\begin{array}{l}\text { Only intrastromal } \\
\text { pigment injection } \\
\text { (due to tunnel } \\
\text { formation failure) }\end{array}$ & Black \\
\hline 13 & $\mathrm{~F}$ & 22 & $\begin{array}{c}\text { S/P PK, CTR,Ps-IOL } \\
\text { and GLC }\end{array}$ & CLFP & $\mathrm{LP}(+)$ & Both & Black \\
\hline 14 & M & 37 & TEI, RD, S-oil, BK & CLFP & $\operatorname{LP}(-)$ & Both & Brown \\
\hline 15 & M & 33 & TEI & $\mathrm{CLI}$ & LP (-) & Both & Brown \\
\hline 16 & $\mathrm{~F}$ & 23 & $M C$ and $N$ & CLUW & $\operatorname{LP}(-)$ & Both & Brown \\
\hline
\end{tabular}

(+): Present; (-):Absent; BK: Band keratopathy; CGLC: Congenital glaucoma; CLFP: Contact lens fit problem; CLI: Contact lens intolerance; CLUW: Contact lens unwillingness; CTR: Corneal transplant rejection; F: Female; GLC: Glaucoma; GLCS: Glaucoma surgery: HS: Hydrops sequelae: KCN: Keratokonus: KTP: Keratopigmentation; LP: Light perception; M: Male; MC: Microcornea; MO: Microphthalmus; N: Nistagmus; P: Projection; PK: Penetrating keratoplasty; Ps-IOL: Pseudophakia intraocular lens; RD: Retinal detachment; S/P: Status post; S-oil: Silicone oil;TEl:Traumatic eye injury;WI:War injury. 
The mean length of follow-up was $29.3 \mathrm{I} \pm 15.45$ months (range: 8-52 months). Satisfactory cosmetic results were achieved after intrastromal and superficial KTP in all cases. In 2 of the 16 patients, mild to moderate pigment loss was seen 12 months after the surgery. Superficial KTP was repeated. In 5 patients, minimal pigment loss was seen, but the cosmetic results were satisfactory, so no secondary surgical procedure was required. Pigment leakage was seen underneath the conjunctiva in only I patient. Excision of stained conjunctiva and repeat and re-keratopigmentation led to a satisfactory cosmetic result. There were no cases of inflammatory reaction or side effects associated with KTP procedures, such as pain, foreign-body reaction, corneal de-epithelialization, or neovascularization (Table $3)$. The mean postoperative patient satisfaction score was 4. $18 \pm 0.75$ points (range: $3-5$ points) (Table I).

Patient photographs before and after keratopigmentation are presented in Figures 2-4.

\section{Discussion}

Keratopigmentation, or corneal tattooing, is a procedure that can be used for cosmetic and therapeutic (functional) indications in selected groups of patients (19). Even though its use has been described since ancient times, it is still un- common in clinical use.

Two types of staining material were used in early KTP procedures. One was chemical dyes, including gold and platinum chloride (I). The other was carbon. Carbon impregnation was more difficult and time-consuming than chemical tattooing, but it lasted longer than chemical dyes. Over time, other organic dyes, India ink, and Chinese ink were used in KTP procedures (6). Subsequently, micronized mineral pigments were produced and first used in the practice of KTP in 2010 (16). The histopathological tolerance, immune reactivity, and local toxicity of these pigments have been discussed in the literature (8). Reducing the size of the particles through micronization is an advantage over natural pigments in terms of the chance of developing foreign body reaction $(9,10,20)$. Another major advantage of micronized mineral pigments is the wide range of colors available (8).

As previously reported (16), we used a combination of manual KTP procedures: superficial and intrastromal. The intrastromal surgical technique maintains the integrity of the basement membrane. Whether the injury is mechanical, chemical, or traumatic, basement membrane trauma causes recurrent corneal epithelial erosion (2I). The intrastromal surgical technique is faster and provides a more homoge-

Table 3. Complications, follow-up, and patient satisfaction scores after superficial keratopigmentation

\begin{tabular}{|c|c|c|c|c|c|c|c|}
\hline Patient no & $\begin{array}{l}\text { Corneal de- } \\
\text { epithelialization }\end{array}$ & $\begin{array}{l}\text { Pigment } \\
\text { loss }\end{array}$ & $\begin{array}{c}\text { Corneal } \\
\text { perforation }\end{array}$ & $\begin{array}{l}\text { Pigment } \\
\text { leakage }\end{array}$ & $\begin{array}{c}\text { Secondary surgical } \\
\text { procedure }\end{array}$ & $\begin{array}{l}\text { Follow-up } \\
\text { (months) }\end{array}$ & $\begin{array}{c}\text { Satisfaction } \\
\text { score }\end{array}$ \\
\hline I & - & - & - & - & - & 14 & 4 \\
\hline 2 & - & - & - & - & - & 8 & 3 \\
\hline 3 & - & + & - & - & Not required & 52 & 5 \\
\hline 4 & - & + & - & - & Not required & 48 & 4 \\
\hline 5 & - & - & - & - & - & 35 & 5 \\
\hline 6 & - & + & - & - & Not required & 38 & 4 \\
\hline 7 & - & - & - & - & - & 30 & 3 \\
\hline 8 & - & + & - & - & S-KTP-repeated & 51 & 5 \\
\hline 9 & - & - & - & - & - & 25 & 4 \\
\hline 10 & - & + & - & - & S-KTP-5 months later & 29 & 4 \\
\hline 11 & - & + & - & - & Not required & 26 & 5 \\
\hline \multirow[t]{2}{*}{12} & - & - & - & Conjunctival & Excision of stained & & \\
\hline & & & & staining & conjunctiva and re-KTP & 19 & 4 \\
\hline 13 & - & - & - & - & - & 10 & 5 \\
\hline 14 & - & + & - & - & Not required & 52 & 5 \\
\hline 15 & - & - & - & - & - & 22 & 3 \\
\hline 16 & - & - & - & - & - & 10 & 4 \\
\hline
\end{tabular}

(-):Absent; (+): Present; S-KTP: Superficial keratopigmentation. 


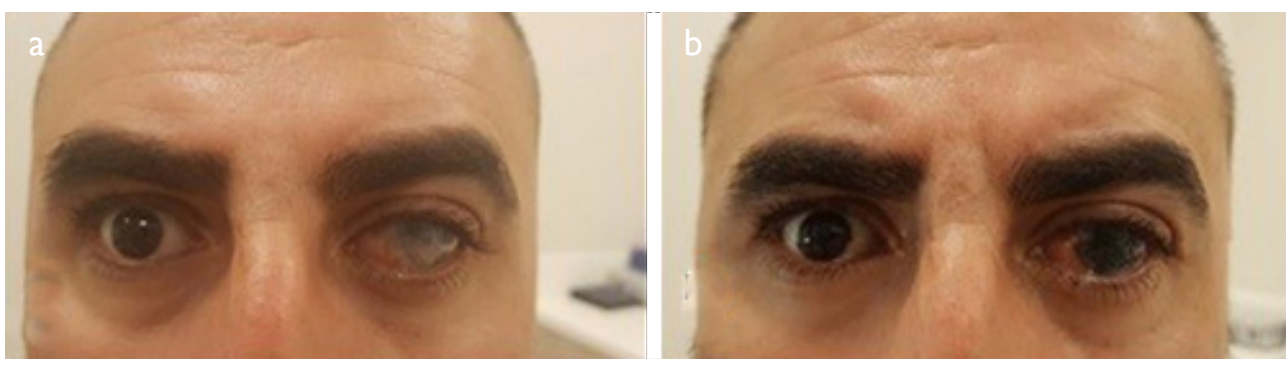

Figure 2. A 39-year-old male with corneal and scleral thinning and prosthetic contact lens intolerance. (a) Before keratopigmentation; (b) After keratopigmentation.
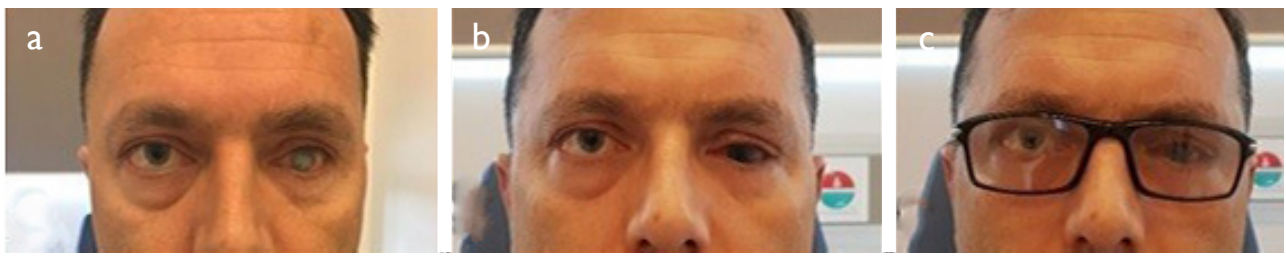

Figure 3. A 45-year-old male with band keratopathy who did not want to use a prosthetic contact lens. (a) Before keratopigmentation; (b, c) After keratopigmentation.
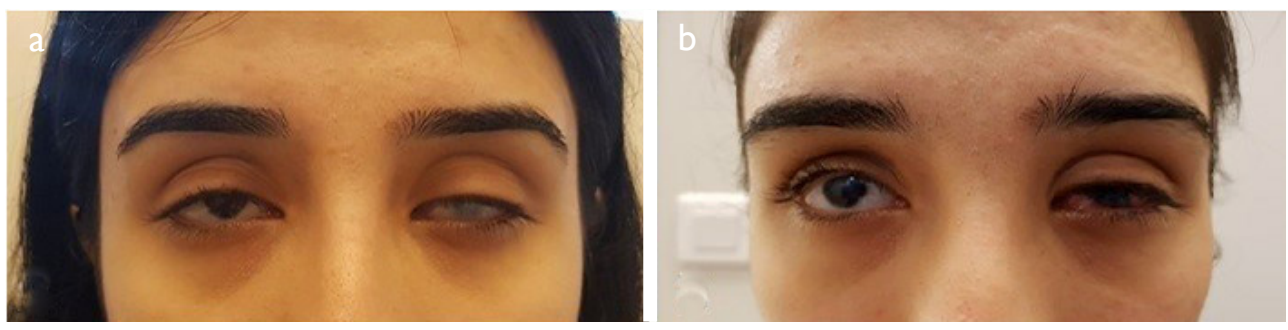

Figure 4. An 18-year-old male with microphthalmus and nistagmus and a poor contact lens fit. (a)

Before keratopigmentation; (b) After keratopigmentation.

neous appearance to the pigmented cornea and has a less symptomatic postoperative recovery because the corneal surface is untouched and staining pigments are not exposed to the tear film.

Some authors have suggested femtosecond-assisted keratopigmentation (FAK), which uses lamellar pockets to predict the configuration and distribution of the pigments into the stroma $(\mathrm{II}, 12)$. This technique has been reported to be more precise, safer, and easier to perform, based on the tunnel formation and good wound healing, (II) and it is well tolerated by patients (22). However, some limitations have also been reported for FAK (23). First of all, it is necessary that there be no corneal damage and no retinal abnormalities because suction may worsen corneal integrity and can cause peripheral retinal holes or tears. In addition, tunnel formation requires sufficient corneal thickness. Furthermore, femtosecond laser software may not be sufficiently adequate to create a wide peripheral tunnel (II).

Limitations of our study include a small number of patients, a wide range of follow-up, and a lack of standardization. In addition, we have portrait photographs of all of the patients, but have anterior segment photographs for only a limited number.

\section{Conclusion}

In conclusion, KTP has proven to be effective, not only for cosmetic problems, such as corneal scars $(16,19)$, but also in cases of functional problems, such as glare sensitivity, photophobia, monocular diplopia due to traumatic iris loss, iridectomy, or iris atrophy $(11-13,19,24)$. However, further studies are necessary in order to further refine effective techniques and pigments. Complications are most likely to be related to the learning curve for the procedure (20). Corneal KTP could have a great impact from both therapeutic and cosmetic perspectives in future ophthalmic surgical practice $(8,10)$. KTP is a safe surgical procedure that is relatively easy to learn and perform, does not require expensive materials, and could avoid more extensive and invasive reconstructive ocular procedures (16).

\section{Disclosures}

Ethics Committee Approval: The Ethics Committee of Koç University provided the ethics committee approval for this study (23.12.2019-2019.409 .IRB2.130).

Peer-review: Externally peer-reviewed. 
Conflict of Interest: None declared.

Authorship Contributions: Involved in design and conduct of the study (MZK, AS, OM); preparation and review of the study (MZK, AS); data collection (MZK, AYT, CK); and statistical analysis (MZK, CK).

\section{References}

I. Mannis MJ, Eghbali K, Schwab IR. Keratopigmentation: a review of corneal tattooing. Cornea 1999;18:633-7.

2. Rodriguez AE, Amesty MA, El Bahrawy M, Rey S, Alio Del Barrio J, Alio JL. Superficial Automated Keratopigmentation for Iris and Pupil Simulation Using Micronized Mineral Pigments and a New Puncturing Device: Experimental Study. Cornea 2017;36:1069-75. [CrossRef]

3. Reed JW. Corneal tattooing to reduce glare in cases of traumatic iris loss. Cornea 1994;13:40 I-5. [CrossRef]

4. Remky A, Redbrake C, Wenzel M. Intrastromal corneal tattooing for iris defects. J Cataract Refract Surg 1998;24:I 285-7.

5. Ziegler SL. Multicolor Tattooing of the Cornea. Trans Am Ophthalmol Soc 1922;20:7I-87.

6. Duggan JN, Nanavati BP. Tattooing of Corneal Opacity With Gold and Platinum Chloride. Br J Ophthalmol 1936;20:4I9-25.

7. Fujita $\mathrm{H}$, Ueda A, Nishida T, Otori T. Uptake of india ink particles and latex beads by corneal fibroblasts. Cell Tissue Res 1987;250:25I-5. [CrossRef]

8. Amesty MA, Alio JL, Rodriguez AE. Corneal tolerance to micronised mineral pigments for keratopigmentation. $\mathrm{Br} \mathrm{J} O \mathrm{Oph}-$ thalmol 20|4;98: I756-60. [CrossRef]

9. Alió JL, Rodriguez AE, El Bahrawy M, Angelov A, Zein G. Keratopigmentation to Change the Apparent Color of the Human Eye: A Novel Indication for Corneal Tattooing. Cornea 2016;35:431-7. [CrossRef]

10. Amesty MA, Rodriguez AE, Hernández E, De Miguel MP, Alio JL. Tolerance of Micronized Mineral Pigments for Intrastromal Keratopigmentation: A Histopathology and Immunopathology Experimental Study. Cornea 20 16;35: I 199-205. [CrossRef]

I I. Alió JL, Rodriguez AE, Toffaha BT, Piñero DP, Moreno LJ. Femtosecond-assisted keratopigmentation for functional and cosmetic restoration in essential iris atrophy. J Cataract Refract Surg 201 I;37:1744-7. [CrossRef]

12. Alio JL, Rodriguez AE, Toffaha BT, El Aswad A. Femtosec- ond-assisted keratopigmentation double tunnel technique in the management of a case of Urrets-Zavalia syndrome. Cornea 20|2;3|:|07|-4. [CrossRef]

I3. Alio JL, Rodriguez AE, Toffaha BT. Keratopigmentation (corneal tattooing) for the management of visual disabilities of the eye related to iris defects. $\mathrm{Br} J$ Ophthalmol 20I I;95:I397-40I.

14. Laria C, Alió JL, Piñero DN. Intrastromal corneal tattooing as treatment in a case of intractable strabismic diplopia (double binocular vision). Binocul Vis Strabismus Q 2010;25:238-42.

15. Hoeyberghs JL. Fortnightly review: cosmetic surgery. BMJ 1999;3 18:512-6. [CrossRef]

16. Alio JL, Sirerol B, Walewska-Szafran A, Miranda M. Corneal tattooing (keratopigmentation) with new mineral micronised pigments to restore cosmetic appearance in severely impaired eyes. Br J Ophthalmol 2010;94:245-9. [CrossRef]

17. Yildirim N, Basmak H, Sahin A. Prosthetic contact lenses: adventure or miracle. Eye Contact Lens 2006;32:102-3. [CrossRef]

18. Al-Shymali O, Rodriguez AE, Amesty MA, Alio JL. Superficial Keratopigmentation: An Alternative Solution for Patients With Cosmetically or Functionally Impaired Eyes. Cornea 2019;38:54-61. [CrossRef]

19. Pitz S, Jahn R, Frisch L, Duis A, Pfeiffer N. Corneal tattooing: an alternative treatment for disfiguring corneal scars. $\mathrm{Br} \mathrm{J} O \mathrm{Ph}$ thalmol. 2002;86(4):397-9. [CrossRef]

20. Alio JL, Al-Shymali O, Amesty MA, Rodriguez AE. Keratopigmentation with micronised mineral pigments: complications and outcomes in a series of 234 eyes. $\mathrm{Br} \mathrm{J}$ Ophthalmol 2018;102(6):742-7. [CrossRef]

2I. Panda A, Mohan M, Chawdhary S. Corneal tattooing--experiences with "lamellar pocket procedure". Indian J Ophthalmol 1984;32(5):408-II.

22. Ricardo JR, Medhi J, Pineda R. Femtosecond laser-assisted keratopigmentation for the management of visual disabilities due to peripheral iridectomies. J Glaucoma 20I5;24(4):e22-4. [CrossRef]

23. Ferrari F, van Haselen R. The Safety and Effectiveness of a Novel Annular Keratopigmentation Method: A Case Report. Case Rep Ophthalmol 2018;9(I):35-42. [CrossRef]

24. Burris TE, Holmes-Higgin DK, Silvestrini TA. Lamellar intrastromal corneal tattoo for treating iris defects (artificial iris). Cornea 1998; I7(2): 169-73. [CrossRef] 